\title{
Percutaneous liver biopsy practice patterns among Canadian hepatologists
}

\author{
Mohammed Aljawad MD FRCPC ${ }^{1}$, Eric M Yoshida MD FRCPC ${ }^{2}$, Julia Uhanova MD PhD ${ }^{3}$, \\ Paul Marotta MD FRCPC ${ }^{1}$, Natasha Chandok MD MPH FRCPC ${ }^{1,3}$
}

\begin{abstract}
M Aljawad, EM Yoshida, J Uhanova, P Marotta, N Chandok. Percutaneous liver biopsy practice patterns among Canadian hepatologists. Can J Gastroenterol 2013;27(11):e31-e34.
\end{abstract}

BACKGROUND: Percutaneous liver biopsy (PLB) is the standard procedure to obtain histological samples essential for the management of various liver diseases. While safe, many hepatologists no longer perform their own PLBs; the reasons for this practice shift are unknown.

OBJECTIVE: To describe the attitudes, practice patterns and barriers to PLB among hepatologists in Canada.

METHODS: A survey was distributed to all hepatologists in Canada. RESULTS: Thirty-two of 40 (80\%) hepatologists completed the survey; the majority of respondents were male $(72 \%)$ and had been in practice for $>5$ years in an academic setting. Fifty-six per cent of hepatologists referred all PLBs to radiology, and only $19 \%$ of hepatologists reported performing their own PLBs most or all of the time. There were no sex differences nor were there differences based on years in practice. Fifty per cent of respondents who performed PLB routinely used ultrasound, and PLBs are performed in equal frequency in an ambulatory procedure area (50\%) versus the endoscopy suite (36\%). For almost one-half of hepatologists (47\%), their performance of PLBs decreased in the past five years. The majority of respondents at an academic centre $(75 \%)$ reported access to FibroScan (Echosens, France), and most estimated a resultant $25 \%$ to $50 \%$ reduction in the need for PLBs. Lack of resources, patient preference and suboptimal reimbursement were the most common reasons cited for not performing PLBs.

CONCLUSION: Most hepatologists in Canada do not perform PLBs to the extent that they did in the past, but refer to radiology. The reasons for this shift in practice include lack of resources, improved perception of safety and patient preference. Where available, FibroScan resulted in a perceived $25 \%$ to $50 \%$ reduction in required liver biopsies.

Key Words: Liver biopsy; Liver disease; Practice patterns

\section{Les modèles de pratique en matière de biopsie hépatique percutanée chez les hépatologues canadiens}

HISTORIQUE : La biopsie hépatique percutanée (BHP) est l'intervention standard pour obtenir des échantillons histologiques essentiels à la prise en charge de diverses maladies hépatiques. Bien qu'elle soit sécuritaire, de nombreux hépatologues ne l'exécutent plus eux-mêmes, sans qu'on sache pourquoi.

OBJECTIF : Décrire les attitudes, les modèles de pratique et les obstacles à la BHP chez les hépatologues du Canada.

MÉTHODOLOGIE : Tous les hépatologues du Canada ont reçu un sondage.

RÉSULTATS : Trente-deux des 40 hépatologues (80\%) ont rempli le sondage, dont la majorité étaient des hommes (72\%) et exerçaient en milieu universitaire depuis plus de cinq ans. Cinquante-six pour cent des hépatologues aiguillaient toutes les BHP en radiologie, et seulement $19 \%$ déclaraient effectuer leurs propres BHP dans la plupart ou la totalité des cas. On ne constatait aucune différence selon le sexe ou les années de pratique. Cinquante pour cent des répondants qui effectuaient systématiquement les BHP le faisaient par échographie, et les BHP étaient exécutées tout autant en consultations externes (50\%) qu'en salle d'endoscopie (36\%). Près de la moitié des hépatologues $(47 \%)$ avaient réduit leur nombre de BHP depuis cinq ans. La majorité des répondants d'un centre universitaire (75\%) signalaient l'accès au FibroScan (Echosens, France), et la plupart estimaient que cet appareil réduisait de $25 \%$ à $50 \%$ la nécessité d'effectuer des BHP. Le manque de ressources, les préférences des patients et le remboursement sous-optimal étaient les principales raisons citées pour ne pas effectuer de BHP.

CONCLUSION : La plupart des hépatologues du Canada n'effectuent pas autant de BHP que par le passé, mais aiguillent leurs patients en radiologie. Ce changement de pratique s'explique par le manque de ressources, une meilleure perception de la sécurité et la préférence du patient. Lorsqu'elle est accessible, le FibroScan suscitait une réduction perçue de $25 \%$ à $50 \%$ des biopsies hépatiques requises.

Ultrasound guidance for routine PLBs is now the standard of care advocated by multisociety guidelines, especially in situations in which it is difficult to clinically identify the liver's edge, as in obesity $(1,6)$. Although data regarding the routine use of ultrasound guidance are inconsistent, many experts contend that ultrasound guidance for PLBs is associated with decreased rates of serious complications compared with standard percussion-guided techniques $(6,7)$. Interestingly, there is no evidence that real-time ultrasound is superior to ultrasoundguided marking as demonstrated by Manolakopoulos et al (8), who determined no significant difference in rates of complications between the two methods among 631 patients.

Perhaps because of the essential role now played by ultrasound in PLB, radiologists, rather than hepatologists or gastroenterologists, have performed an increased proportion of PLBs in recent years. For instance, in a study from the University of Calgary (Calgary, Alberta), the proportion of PLBs performed by radiologists increased from $73 \%$ in 1994 to $98 \%$ in 2002; the reasons for this increase were not explored within seven days (4).

\footnotetext{
${ }^{1}$ Department of Medicine, Western University, London, Ontario; ${ }^{2}$ University of British Columbia, Vancouver, British Columbia; ${ }^{3}$ University of Manitoba, Wimmipeg, Manitoba

Correspondence: Dr Natasha Chandok, Western University, 339 Windermere Road, London, Ontario N5X 2 T2.

Telephone 905-494-2120 ext 57994, fax 519-663-3858, e-mail dr.n.chandok@gmail.com

Received for publication February 12, 2013. Accepted September 15, 2013
} 
in their study; however, a shift in practice patterns clearly occurred (5). Similarly, studies from the United States revealed a 25\% to $30 \%$ decline in the number of clinicians who previously performed PLBs, with the procedure instead deferred to radiologists $(9,10)$. The reasons cited for this change included concerns regarding the procedure safety, low reimbursement and lack of resources.

Although PLB provides invaluable information to aid in the management of many patients with liver disease, it has several limitations. Aside from being invasive, resource intensive, and undesirable and potentially harmful to some patients, there are multiple technical concerns that render liver biopsy a less-than-perfect gold-standard test. For instance, liver parenchymal changes in a variety of diseases are often unevenly distributed in the organ, and PLB samples a relatively small portion of the liver (one per 50,000 ) that can lead to sampling error. This can lead to underdiagnosis of liver cirrhosis in a sizeable proportion of cases selected for biopsy (15\% to 35\%), as has been shown in previous publications $(11,12)$. There is also the additional issue of inadequate sample size, a frequent phenomenon demonstrated in a large French study that concluded that the vast majority of biopsies fall short of the $2.5 \mathrm{~cm}$ benchmark needed for sufficient sample $(13,14)$. To minimize sampling error, the American Association for the Study of Liver Diseases recommends liver sample length of $2 \mathrm{~cm}$ to $3 \mathrm{~cm}$ with at least 11 complete portal tract areas (1). Another technical barrier to the utility of PLB is sampling variability. In a study by Regev et al (11), there was a difference of at least one grade in $24.2 \%$ and at least one stage in $33.1 \%$ of cases between the right and left lobes among 124 patients who underwent laparoscopic-guided biopsy of right and left hepatic lobes. However, differences of more than one stage or grade were uncommon (11). Interpretation error by pathologists during assessment of liver histopathology is another recognized limitation. Although multiple staging score systems have been developed to standardize the evaluation of liver biopsy and to minimize interpretation error, several studies that evaluated interobserver variability among pathologists showed significant discordance that can reach up to $40 \%$ to $50 \%(12,15)$.

The need for safer, less resourceful and more convenient methods to stage liver disease has led to the development of various noninvasive tests to evaluate liver fibrosis. These tests have been used to stage liver diseases and guide management. Noninvasive tests include serum markers, liver imaging, and sonographic or magnetic resonance elastography. Several serum markers have been evaluated thoroughly in the literature, including direct and indirect markers, among the most widely validated of which is FibroTest (FibroSure, LabCorp, USA). Meta-analyses have shown excellent accuracy of FibroTest in identifying no or minimal fibrosis and cirrhosis, but low diagnostic value to discriminate intermediate stages of fibrosis $(16,17)$. Furthermore, FibroTest is costly, and can only be performed in validated reference laboratories due to variability of components in assays and analyzers, making it a poor modality for serial monitoring and population screening (18).

Sonographic transient elastography (FibroScan, Echosens, France) has emerged as a quick, painless and reproducible way to assess liver fibrosis at the bedside. In a multicentre prospective study (the FIBROSTIC study), the accuracy of FibroScan for diagnosing cirrhosis was high (area under ROC curve [AUROC] 0.90) compared with common serum biomarkers including FibroTest, Fibrometer, Hepascore and aspartate aminotransferase to platelet ratio index (APRI; AUROC 0.77 to 0.86 ), but performance accuracy in predicting significant fibrosis was moderate (AUROC 0.72 to 0.78) (19). A meta-analysis of 50 studies that evaluated the performance of FibroScan for the staging of liver fibrosis (20) showed similar results with high accuracy for diagnosing liver cirrhosis (AUROC 0.94) and moderate accuracy for diagnosing significant fibrosis (AUROC 0.84). FibroScan requires certain expertise to interpret and apply to the care of patients with liver disease, especially because the definition of a reliable FibroScan reading with appropriate interpretation within the clinical context is still evolving. A recent French study has shown a significant probability of failing to diagnose liver cirrhosis that can reach up to $30 \%$ due to the inherent unreliability parameters associated with FibroScan (21). Currently, noninvasive tests, such as FibroScan, are not widely available for clinical practice outside of tertiary centres in Canada. For example, in Canada, FibroScan machines are almost exclusively confined to academic centres with large liver units ( $<10$ estimated nationwide), posing a practical limitation to use of this modality for widespread screening.

Magnetic resonance elastography (MRE) is another novel, noninvasive technique for assessing liver fibrosis. Unlike FibroScan, MRE has the advantage of assessing the entire liver, which makes it potentially more reliable than other modalities due to the heterogeneous nature of liver injury and fibrosis in many diseases. Huwart et al (22) reported better diagnostic accuracy and higher technical success rate of MRE compared with FibroScan (22). Furthermore, in a metaanalysis, MRE had high diagnostic accuracy in discriminating intermediate stages of fibrosis (23). Although MRE could theoretically reduce the need of PLB for liver fibrosis evaluation and may be superior to most noninvasive techniques to assess for hepatic fibrosis, it is not without limitations. These limitations include higher costs and limited availability of equipment and/or expertise outside of tertiary centres, rendering MRE impractical.

Liver disease is a leading cause of morbidity and mortality worldwide, particularly among middle-age adults in whom liver disease is among the top five causes of mortality, and a significant cause of morbidity and health care expenditure (24). The role of PLB in the assessment of liver diseases requires an updated re-examination, especially with the rapid advancements in noninvasive tests now available in modern practice. The aim of the present study was to describe the attitudes, current practice patterns and potential barriers of PLB among hepatologists in Canada.

\section{METHODS}

\section{Survey participants}

With the aid of the Canadian Association for the Study of Liver Disease directory and gastroenterology division heads at academic centres, all hepatologists in Canada were contacted by secure e-mail or telephone to describe the study. For hepatologists who provided informed consent to participate, a questionnaire was sent via secure e-mail or post between August 2012 and January 2013. Subjects who did not complete the 21-question survey received two e-mail reminders one month after survey distribution. The study was approved by the Office of Research Ethics at Western University, London, Ontario.

\section{Data collection}

A comprehensive survey was distributed to participants.

\section{Statistical analysis}

The frequencies of each survey response were tabulated as percentages. The $\chi^{2}$ test was used to evaluate the differences in responses between various categories of responders (eg, male versus female hepatologists or response according to years of practice). Statistical testing for trends were performed using Armitage test for trend in proportions.

\section{RESULTS}

Thirty-two of 40 (80\%) Canadian hepatologists completed the survey, and $72 \%$ were male. Almost one-half of all respondents (44\%) practiced in Ontario (14 of 32), 19\% (six of 32) were from Alberta, 16\% (five of 32) from British Columbia, 12.5\% (four of 32) from Manitoba and one $(3 \%)$ each were from Newfoundland and Labrador, New Brunswick and Quebec. The majority (81\%) of hepatologists practice in academic centres, and one-half of respondents practice at a liver transplant centre.

Slightly more than one-half of respondents (53\%) had been in practice for $>10$ years. As shown in Figure 1, there was a clear temporal trend in the practice of hepatology according to sex, with female hepatologists entering practice more recently (Armitage test for trend in proportions $\mathrm{P}<0.02$ ). 


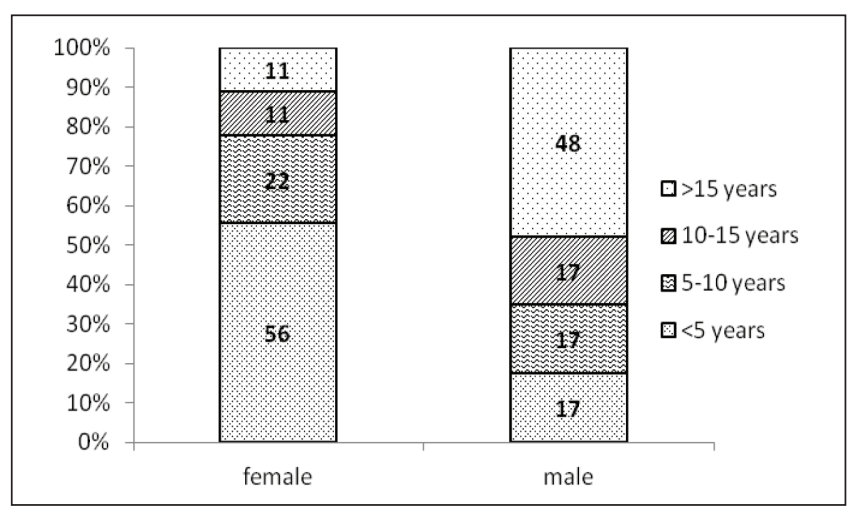

Figure 1) Years of practice according to sex

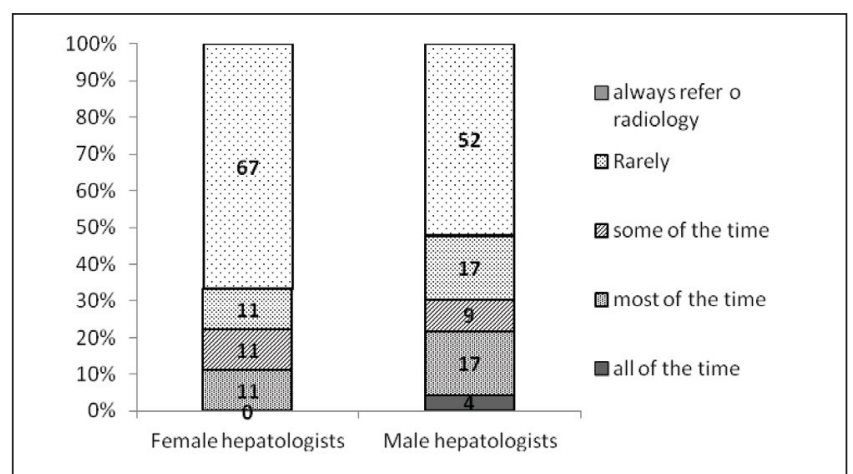

Figure 2) Frequency of performance of percutaneous liver biopsy in male verus female hepatologists

Only 44\% of hepatologists perform PLBs; the remainder refer their patients to radiology. There were no statistical differences in the frequency of performing PLB by male and female hepatologists $(\mathrm{P}=0.91$; test for trends $\mathrm{P}=0.44$ ). As illustrated in Figure 2, only those 'always referring to radiology' (ie, never perform liver biopsies) were considered on the basis of sex (ie, male versus female hepatologists $(52.2 \%$ versus $66.7 \%)$; there was no statistical difference $(\mathrm{P}=0.46)$.

There were no differences in the time in practice and performance of PLB ( $\mathrm{P}=0.11)$ as shown in Figure 3. Forty-seven per cent of respondents stated that the number of PLBs performed in their practice decreased in the past five years, and $31 \%$ of respondents reported that this number decreased in the past 10 years.

There was a significant reduction in the performance of PLB due to the availability of FibroScan $(\mathrm{P}=0.008)$. One-half of hepatologists who have access to this diagnostic modality reported a decrease in PLBs of $25 \%$ to $50 \%$, while $29 \%$ reported a decrease $>50 \%$. Only $8 \%$ (two hepatologists) reported no reduction in PLB (Figure 4).

\section{DISCUSSION}

The present study provides an understanding of current practice patterns and barriers toward PLBs among hepatologists in Canada. The present survey showed a clear trend toward hepatologists performing fewer PLBs. For instance, more than one-half of respondent hepatologists reported a decrease in PLBs in the past five years and, similarly, the majority of respondents do not or no longer perform PLBs, but instead refer their patients to radiologists exclusively. The reasons for this striking national change in practice include, in decreasing order of frequency: the perception of improved safety by either by the hepatologist or the patient or both (62\%); lack of resources (56\%); and low reimbursement fees (33\%). This observation is comparable with previous studies in the United States where one-third to one-half of hepatologists no longer perform PLBs $(9,10,25)$.

In our study, there were several factors that, surprisingly, did not influence a hepatologist's decision to perform PLB. Interestingly, for example, there was no sex discrepancy in practice patterns according

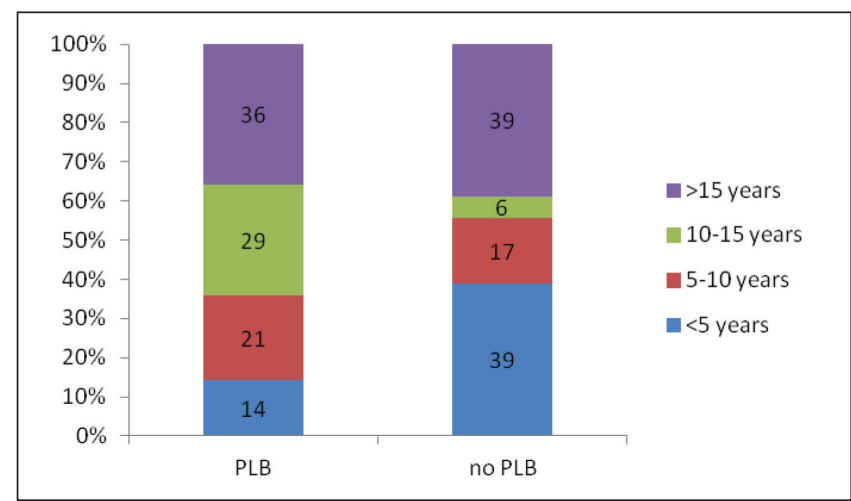

Figure 3) Performance of percutaneous liver biopsy (PLB) according to years of practice

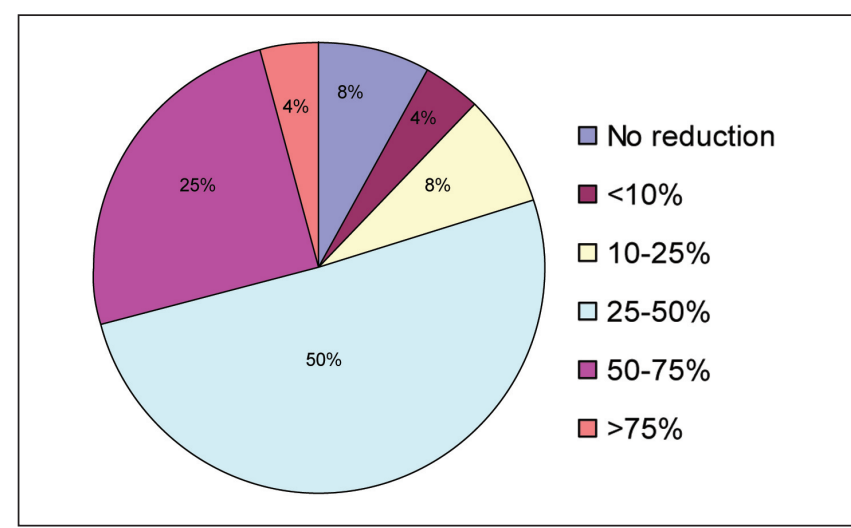

Figure 4) Per cent reduction in percutaneous liver biopsy due to FibroScan (Echosens, France)

to $\chi^{2}$ test or Armitage trend test, with $67 \%$ of female hepatologists, and a comparable $52 \%$ of male hepatologists, not performing PLBs. Additionally, there was no relationship between performing PLBs and years in clinical practice.

Advances in noninvasive tests to stage liver diseases have undoubtedly led to a reduction in PLBs. Seventy-five per cent (24 of 32) of respondents reported access to FibroScan, 92\% (22 of 24) of whom reported a corresponding drop in the need for PLBs. This reduction was quite sizeable, with one-half of respondents (12 of 24) from centres possessing FibroScan estimating a 25\% to 50\% reduction in the need for PLBs, and 30\% (seven of 24) of respondents estimating a 50\% to $75 \%$ reduction. Although FibroScan is not broadly available for clinical practice in Canada at present, it has gained wide acceptance through scientific validation in multiple studies. While limited somewhat by reliability, FibroScan has favourable operative characteristics compared with other noninvasive tests for hepatic fibrosis; this renders FibroScan an attractive modality that may diminish the need for PLBs for many indications and more rapidly facilitate clinical decision making in modern hepatology practice.

Interestingly, although multiple studies have shown that ultrasoundguided PLB is associated with lower rates of complications and postprocedure hospitalizations $(7,26), 54 \%$ of respondents who perform PLBs still use a percussion-guided technique, while $23 \%$ use ultrasound guidance and $23 \%$ use either method. The reason for choosing one technique over another was not explored in the present study, but greater number of years in practice was not correlated with percussion guidance, and lack of available ultrasound machines for use by the hepatologist may have been contributory. Notwithstanding, a cost analysis study by Younossi et al (27) suggested that routine ultrasoundguided PLB is cost effective if the additional cost of ultrasound is $<\$ 102$ per patient. Given the widespread availability of ultrasound and its acceptance as standard-of-care practice for performance of 
PLB, using a percussion technique alone may well have medicolegal consequences in cases of complications from PLB, especially because multiple professional societies recommend the routine use of ultrasound $(1,6)$. Interestingly, all respondents in the present study who use an ultrasound-guided technique obtain real-time images themselves during the procedure rather than having the biopsy site marked by radiologists. Compact, less-expensive ultrasound machines are more readily available now for use by clinicians; this may influence the ability of hepatologists to perform PLBs themselves.

Almost one-half of hepatologists in academic centres do not or no longer perform PLBs. This may have implications on training of future hepatologists. Of the 14 hepatologists practicing in academic centres who continue to perform PLBs, only four (three of whom work at a transplant centre) believed that the teaching of trainees is an influencing factor in their decision to perform PLBs. Concerns regarding hepatology trainees receiving adequate training and competency in PLB were not explicitly explored in the present survey.

The response rate of our survey $(80 \%)$ was satisfactory. We were able to achieve this rate because of the relatively small number of hepatologists in Canada who are tightly linked through the Canadian Association for the Study of Liver for which membership is approximated at $100 \%$. However, our study had several limitations. First, there was regional variation in province of origin of respondents, reflective of practice locations of hepatologists in Canada. For example, there were no respondents from Saskatchewan, while there was only one respondent each from Quebec, New Brunswick, and Newfoundland and Labrador. Such small numbers of hepatologists from several provinces makes it exceedingly difficult to assess for

\section{REFERENCES}

1. Rockey DC, Caldwell SH, Goodman ZD, Nelson RC, Smith AD. Liver biopsy. Hepatology 2009;49:1017-44.

2. van Leeuwen DJ, Wilson L, Crowe DR. Liver biopsy in the mid1990s: Questions and answers. Semin Liver Dis 1995;15:340-59.

3. Seeff LB, Everson GT, Morgan TR, et al. Complication rate of percutaneous liver biopsies among persons with advanced chronic liver disease in the HALT-C trial. Clin Gastroenterol Hepatol 2010;8:877-83.

4. West J, Card TR. Reduced mortality rates following elective percutaneous liver biopsies. Gastroenterology 2010;139:1230-7.

5. Myers RP, Fong A, Shaheen AA. Utilization rates, complications and costs of percutaneous liver biopsy: A population-based study including 4275 biopsies. Liver Int 2008;28:705-12.

6. Grant A, Neuberger J. Guidelines on the use of liver biopsy in clinical practice. British Society of Gastroenterology. Gut 1999;(45 Suppl 4):IV1-IV11.

7. Caturelli E, Giacobbe A, Facciorusso D, et al. Percutaneous biopsy in diffuse liver disease: Increasing diagnostic yield and decreasing complication rate by routine ultrasound assessment of puncture site. Am J Gastroenterol 1996;91:1318-21.

8. Manolakopoulos S, Triantos C, Bethanis S, et al. Ultrasound-guided liver biopsy in real life: Comparison of same-day prebiopsy versus real-time ultrasound approach. J Gastroenterol Hepatol 2007;22:1490-3.

9. Muir AJ, Trotter JF. A survey of current liver biopsy practice patterns. J Clin Gastroenterol 2002;35:86-8.

10. Angtuaco TL, Lal SK, Banaad-Omiotek GD, Zaidi SS, Howden CW. Current liver biopsy practices for suspected parenchymal liver diseases in the United States: The evolving role of radiologists. Am J Gastroenterol 2002;97:1468-71.

11. Regev A, Berho M, Jeffers LJ, et al. Sampling error and intraobserver variation in liver biopsy in patients with chronic HCV infection. Am J Gastroenterol 2002;97:2614-8.

12. Olsson R, Hagerstrand I, Broome U, et al. Sampling variability of percutaneous liver biopsy in primary sclerosing cholangitis. J Clin Pathol 1995;48:933-5.

13. Poynard T, Munteanu M, Imbert-Bismut F, et al. Prospective analysis of discordant results between biochemical markers and biopsy in patients with chronic hepatitis C. Clin Chem 2004;50:1344-55.

14. Bedossa P, Dargere D, Paradis V. Sampling variability of liver fibrosis in chronic hepatitis C. Hepatology 2003;38:1449-57. regional differences in practice patterns. Furthermore, we acknowledge that it is likely that a small minority of hepatologists were not identified due to missing contact information or lack of membership to the Canadian Association for the Study of Liver or oversight. However, because there was no bias in the way recipients of the survey were selected, these inadvertent errors of omission were not believed to introduce selection bias because the survey request was random. Recall bias is another potential limitation because our study relied on self-reported practice patterns over a period of time.

\section{CONCLUSION}

The present study suggests that PLB is becoming a lost art in hepatology practice and, for myriad reasons, PLB is increasingly performed by radiology. The main reasons for this trend can be attributed lack of resources, perception of improved safety when liver biopsy is performed by radiologists, and unsatisfactory reimbursement for PLB to the hepatologist. Additionally, the emergence of novel noninvasive techniques for assessment of liver fibrosis, namely FibroTest and FibroScan, are reducing the need for PLB. We contend that this change in practice pattern with respect to PLB is not necessarily to the detriment of the specialty given the inherent drawbacks of PLB and the rapid advancements in noninvasive techniques that may replace the need for a sizeable proportion of PLBs.

DISCLOSURES: The authors have no financial disclosures or conflicts of interest to declare.

15. Robert M, Sofair AN, Thomas A, et al. A comparison of hepatopathologists' and community pathologists' review of liver biopsy specimens from patients with hepatitis C. Clin Gastroenterol Hepatol 2009;7:335-8.

16. Poynard T, Morra R, Halfon P, et al. Meta-analyses of FibroTest diagnostic value in chronic liver disease. BMC Gastroenterol 2007;7:40.

17. Shaheen AA, Wan AF, Myers RP. FibroTest and FibroScan for the prediction of hepatitis C-related fibrosis: A systematic review of diagnostic test accuracy. Am J Gastroenterol 2007;102:2589-600.

18. Friedrich-Rust M, Rosenberg W, Parkes J, Herrmann E, Zeuzem S, Sarrazin C. Comparison of ELF, FibroTest and FibroScan for the non-invasive assessment of liver fibrosis. BMC Gastroenterol 2010;10:103.

19. Degos F, Perez P, Roche B, et al. Diagnostic accuracy of FibroScan and comparison to liver fibrosis biomarkers in chronic viral hepatitis: A multicenter prospective study (the FIBROSTIC study). J Hepatol 2010;53:1013-21.

20. Friedrich-Rust M, Ong MF, Martens S, et al. Performance of transient elastography for the staging of liver fibrosis: A metaanalysis. Gastroenterology 2008;134:960-74.

21. Boursier J, Zarski JP, de Ledinghen V, et al. Determination of reliability criteria for liver stiffness evaluation by transient elastography. Hepatology 2013;57:1182-91.

22. Huwart L, Sempoux C, Vicaut E, et al. Magnetic resonance elastography for the noninvasive staging of liver fibrosis. Gastroenterology 2008;135:32-40.

23. Wang QB, Zhu H, Liu HL, Zhang B. Performance of magnetic resonance elastography and diffusion-weighted imaging for the staging of hepatic fibrosis: A meta-analysis. Hepatology 2012;56:239-47.

24. Kim WR, Brown RS Jr, Terrault NA, El-Serag H. Burden of liver disease in the United States: Summary of a workshop. Hepatology 2002;36:227-42.

25. Mayoral W, Lewis JH. Percutaneous liver biopsy: What is the current approach? Results of a questionnaire survey. Dig Dis Sci 2001;46:118-27.

26. Lindor KD, Bru C, Jorgensen RA, et al. The role of ultrasonography and automatic-needle biopsy in outpatient percutaneous liver biopsy. Hepatology 1996;23:1079-83.

27. Younossi ZM, Teran JC, Ganiats TG, Carey WD. Ultrasoundguided liver biopsy for parenchymal liver disease: An economic analysis. Dig Dis Sci 1998;43:46-50. 


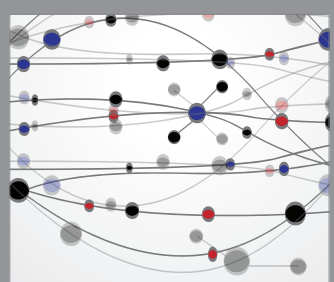

The Scientific World Journal
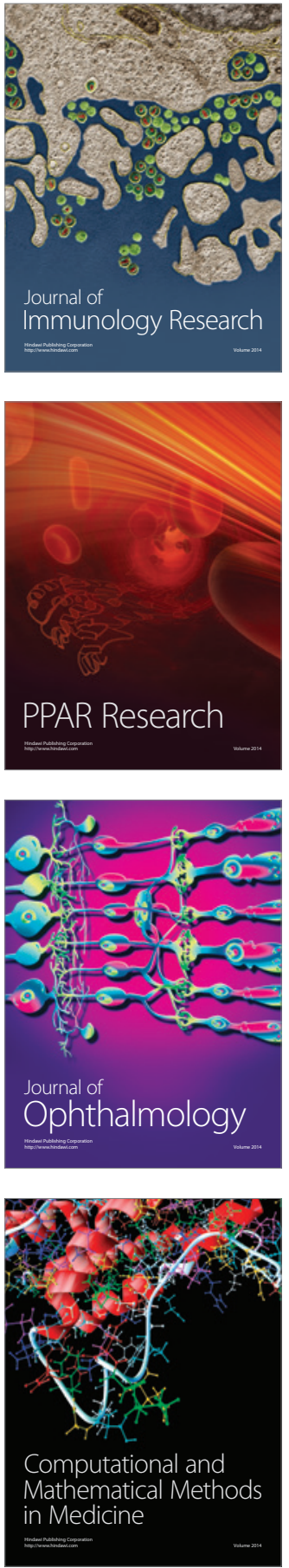

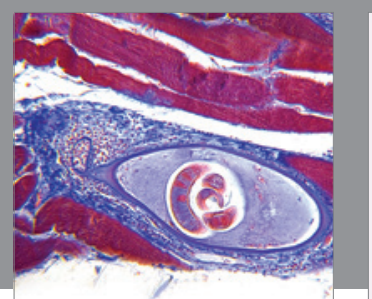

Gastroenterology Research and Practice

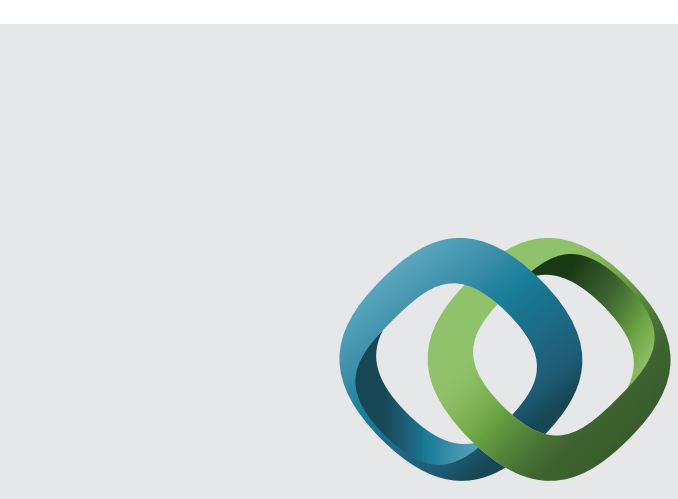

\section{Hindawi}

Submit your manuscripts at

http://www.hindawi.com
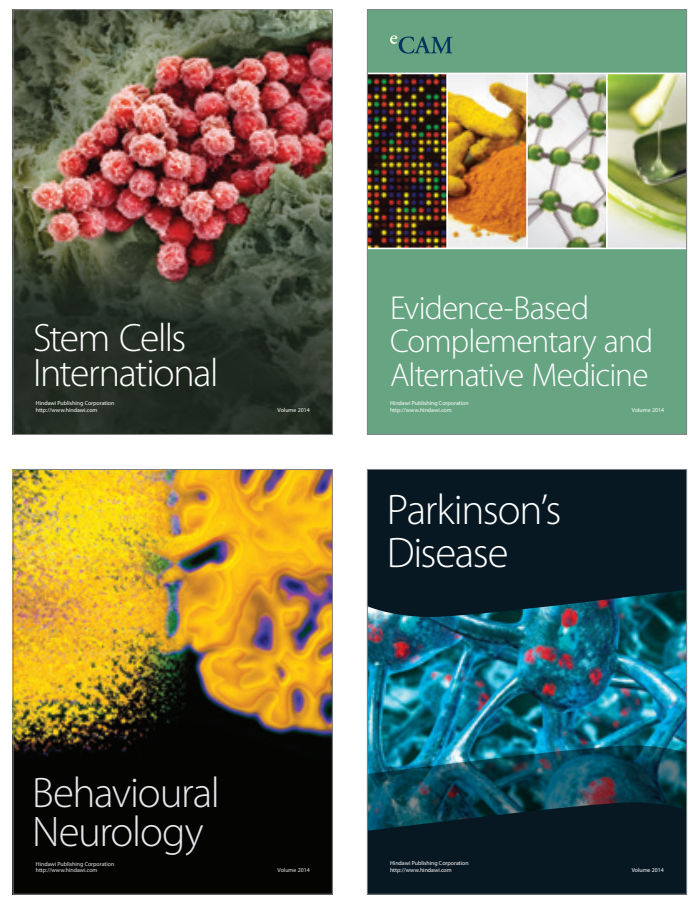
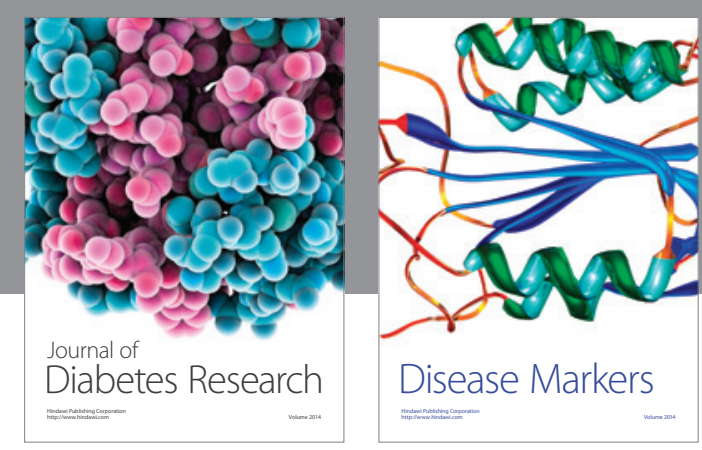

Disease Markers
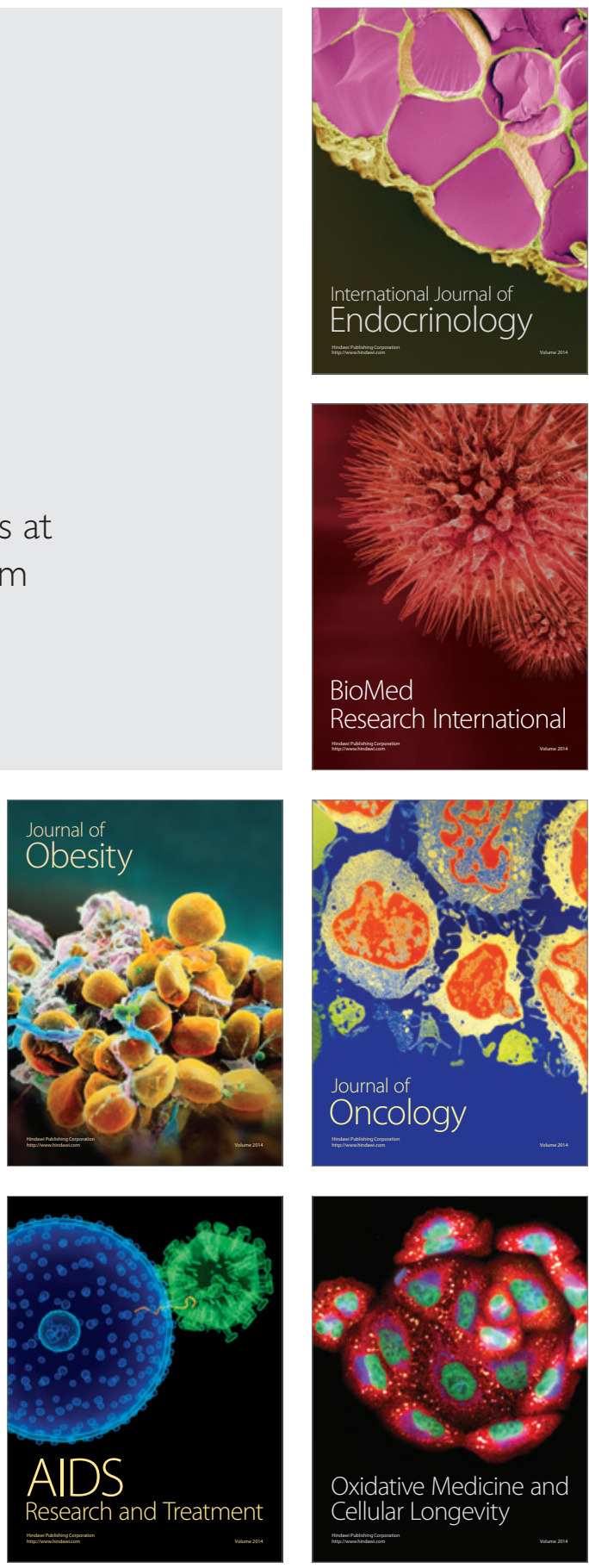